
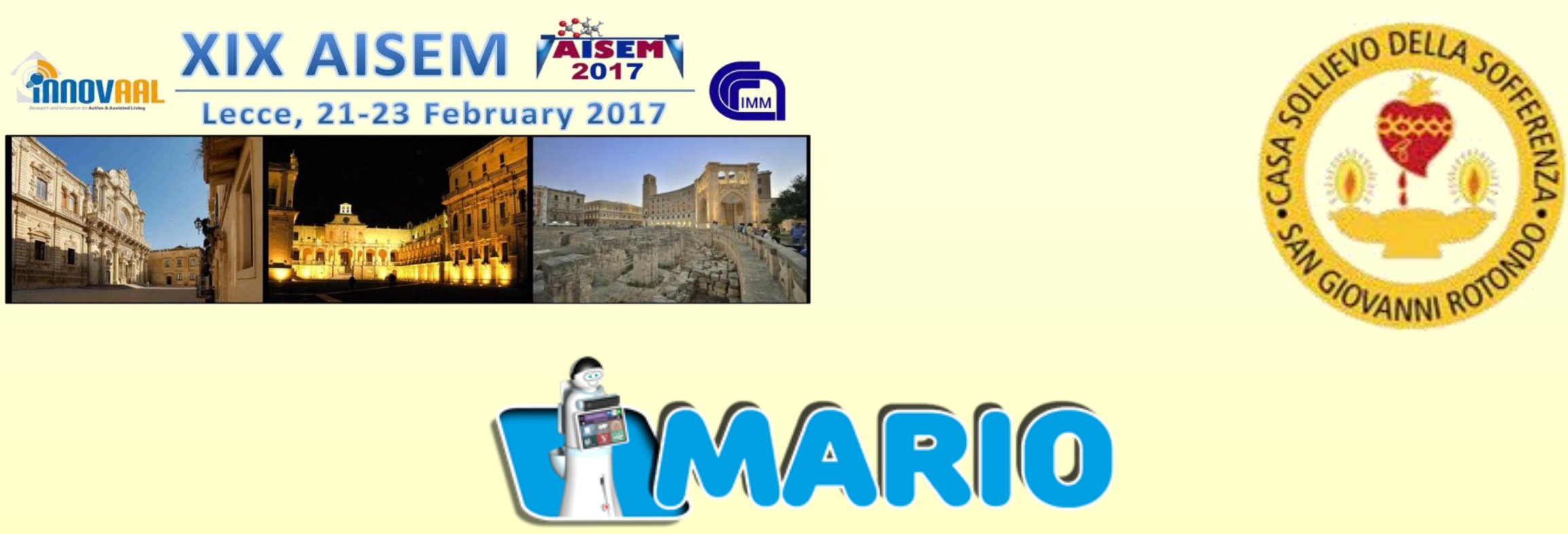

\title{
A Multicenter Survey about Companion Robot Acceptability in Caregivers of Patients with Dementia
}

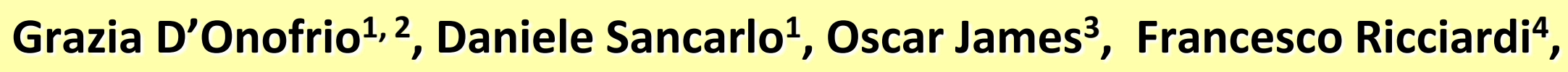
Dympna Casey ${ }^{3}$, Keith Murphy ${ }^{3}$, Francesco Giuliani ${ }^{4}$ and Antonio Greco ${ }^{1}$

${ }^{1}$ Geriatrics Unit \& Laboratory of Gerontology and Geriatrics, Department of Medical Sciences, IRCCS "Casa Sollievo della Sofferenza", San Giovanni Rotondo, Foggia, Italy.

2 The BioRobotics Institute, Scuola Superiore Sant'Anna, Pontedera, Italy

${ }^{3}$ School of Nursing and Midwifery, National University of Ireland, Galway, Ireland.

"ICT, Innovation and Research Unit, IRCCS "Casa Sollievo della Sofferenza", San Giovanni Rotondo, Foggia, Italy. 


\section{Introduction}

\section{Age of Loneliness}

In $205016 \%$ world population over 65 


\section{Introduction}

\section{Dementia}

- Another 20 people

- By 85 one person in every 3 will have dementia

Dementia

worsens over time,

erodes your memory,

$\checkmark$ language,

communication, changes your moods and personality.

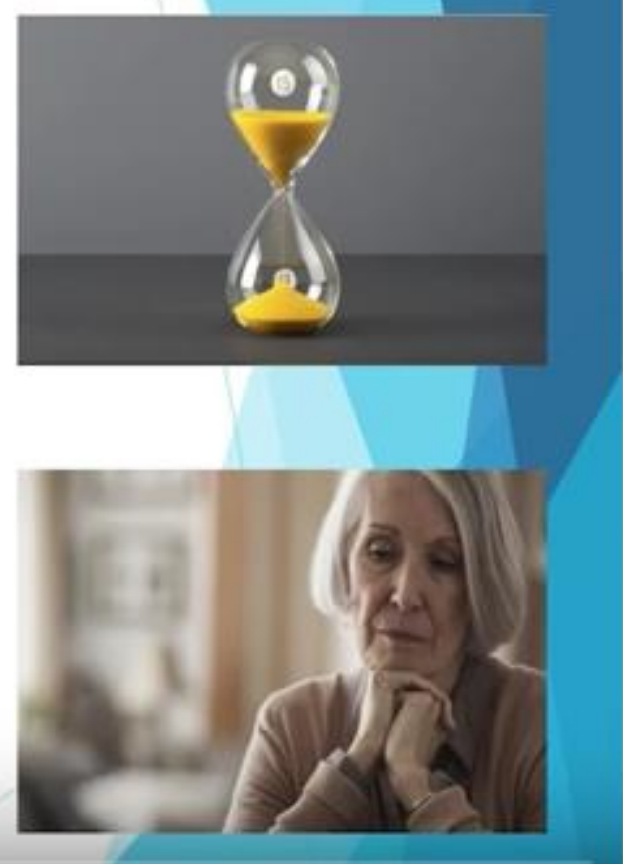




\section{Introduction}

Alzheimer' disease (AD) leads to severe social consequences:

-decreased quality of life and well-being -increased family burdens and health care demand

-longer term utilization of care facilities that generate very significant impacts on health care services demand and consequently costs (Seelye A. et al., 2012).

To fight loneliness and the effects suffered by person with dementia, effective techniques include those that target change of a person's perception of loneliness and those that increase a person's resilience.

Resilience is an adaptive capacity that refers to one's ability to 'bounce back' and cope in the face of adversity.

\section{$2016 \mid \begin{aligned} & \text { Alzheimer's Disease } \\ & \text { Facts and Figures }\end{aligned}$}

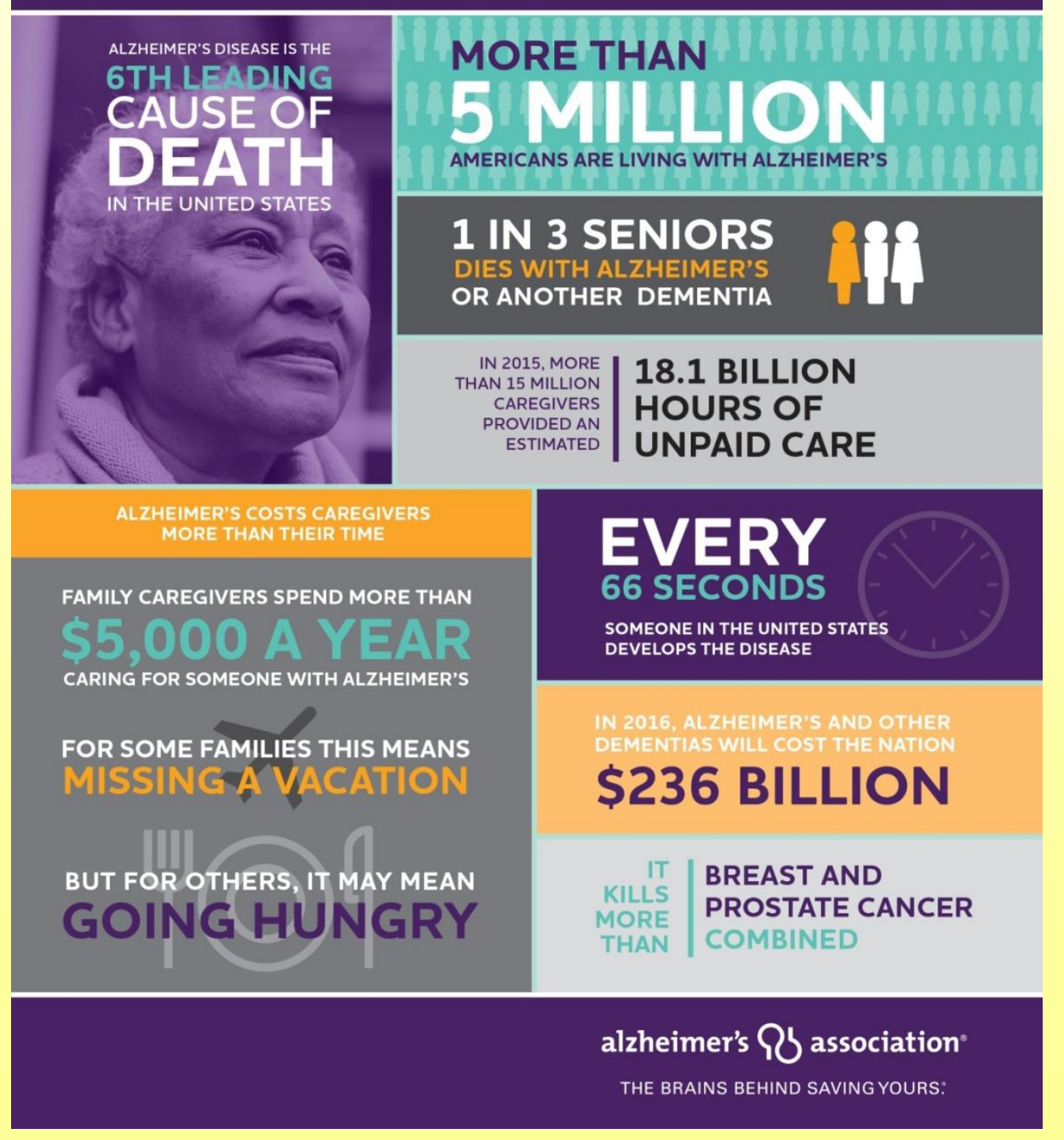


Managing active and healthy aging with use of caring service robots (MARIO)

(February 2015-January 2018)

Information and Communication Technologies (ICT) solutions can be used to increase psychological skills like resilience (Norris et al., 2008), and to manage active and healthy aging with the use of caring service robots as will be explored with the EU funded MARIO project

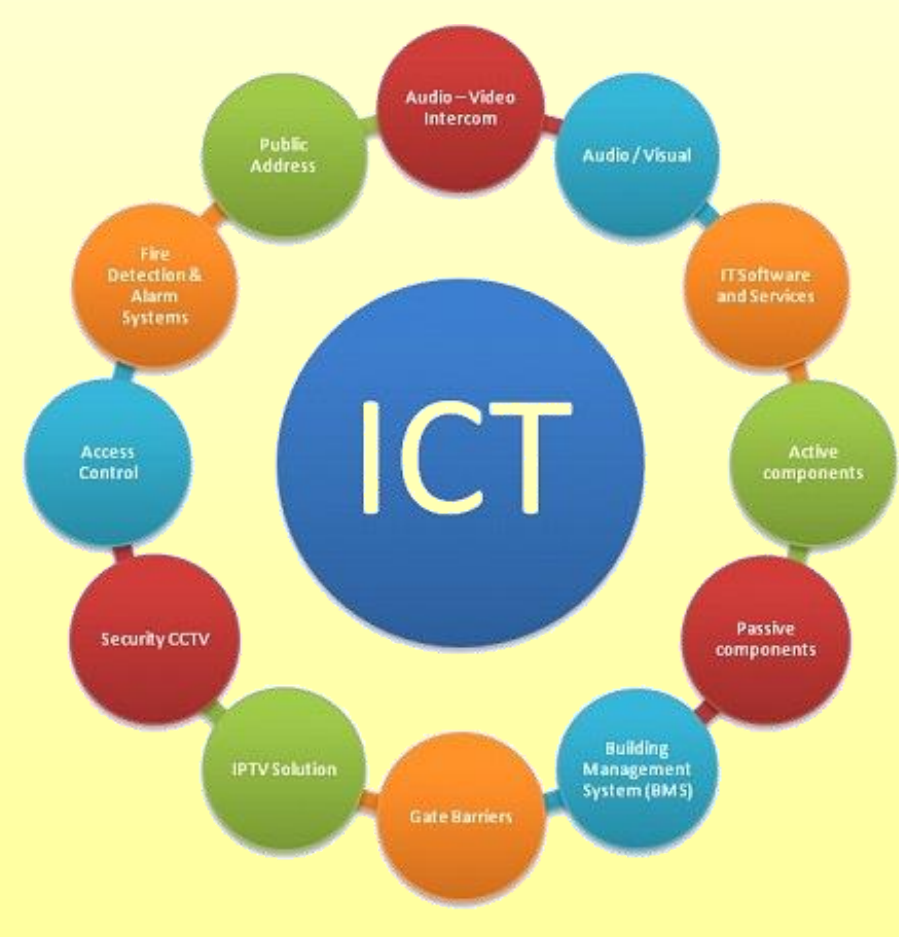
(http://www.mario-project.eu/portal/). 


\section{Partners}

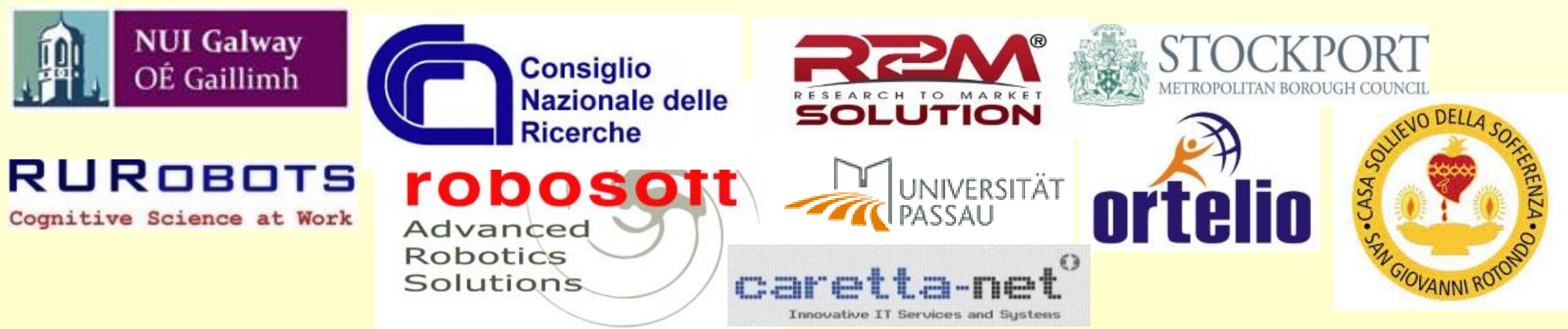

- National University of Ireland, Galway

- ROBOSOFT

- RU Robot

- Ortelio Ltd

- City of Stockport

- Consiglio Nazionale delle Ricerche

- R2M Solution

- Casa Sollievo della Sofferenza Hospital

- Caretta-Net

- University of Passau 


\section{MARIO objectives $1 / 2$}

- To address and make progress on the challenging problems of loneliness, isolation and dementia in older persons through multifaceted interventions delivered by service robots.

- To conduct near project length interaction with end users and assisted living environments.

- To assist caregivers and physicians in the comprehensive geriatric assessment (CGA) through the use of service robots.

- The use of near state of the art robotic platforms that are flexible, modular friendly, low cost and close to market ready. 


\section{MARIO objectives $2 / 2$}

- To make MARIO capable to support and receive "robot applications" similar to the developer and app community for smartphones.

- Through novel advances in machine learning techniques and semantic analysis methods to make MARIO more personable, useful, and accepted by end users (e.g. gain perception of nonloneliness).

- To bring MARIO service robot concepts out of the lab and into industry. 


\section{First model of robot suggested at the begin of the MARIO project}
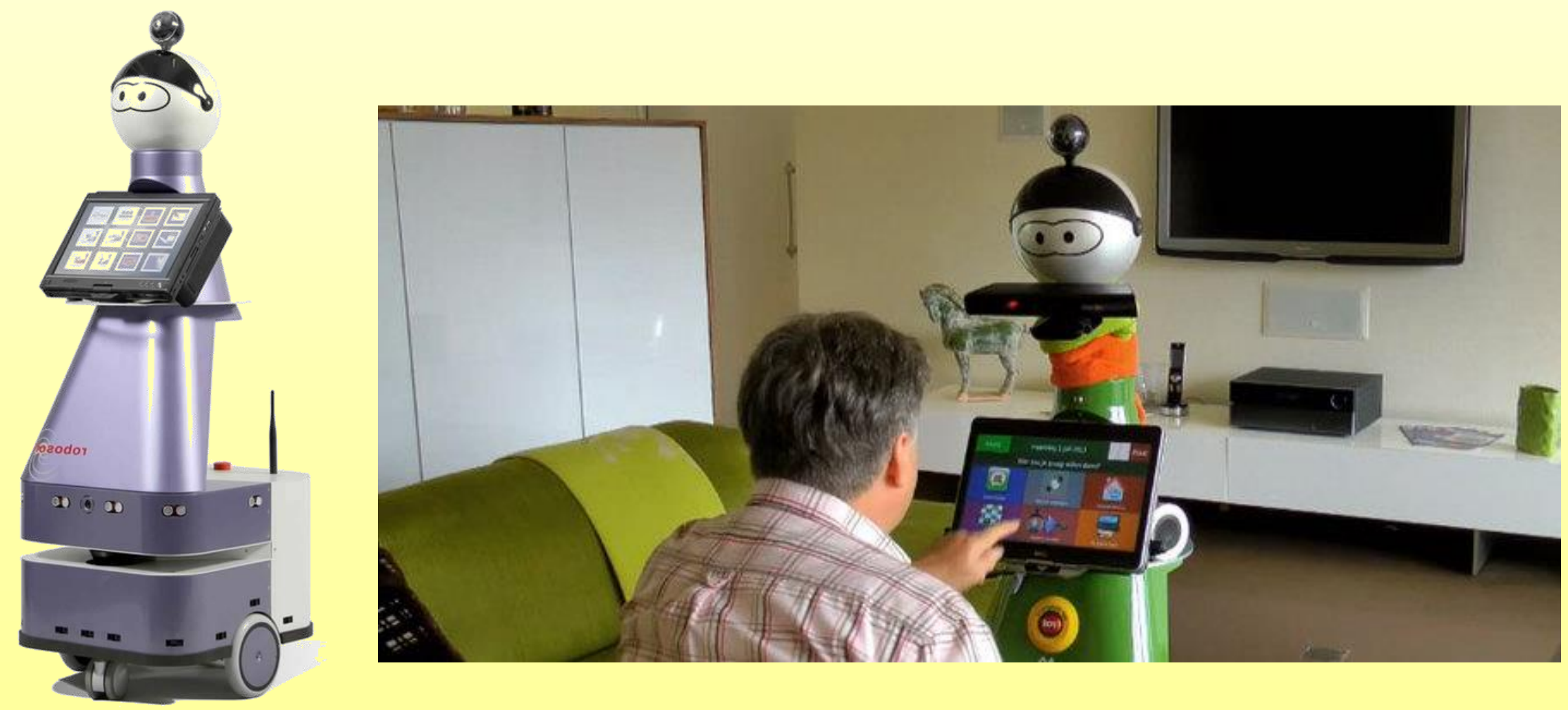


\section{Survey of the needs}

At the first stage of the MARIO project, Focus groups were performed and a questionnaire was designed to find out perceptions of the caregivers about robot companions, especially what they would like such a robot to do for them, and how robots could be designed to build the patient resilience.

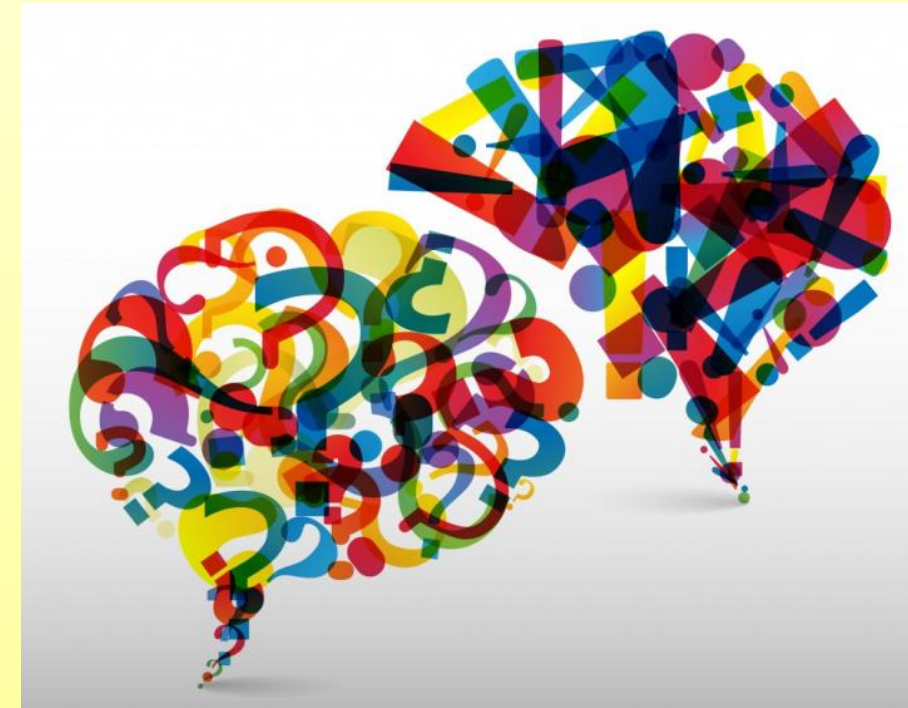




\section{Aims}

The goal of these activities were to determine the needs and preferences of formal and informal caregivers for improving the assistance of dementia patients, and guiding the technological development of MARIO though a questionnaire. 


\section{Focus Groups}

\section{April and May 2015 \\ Geriatrics Unit, Casa Sollievo della Sofferenza, IRCCS, San Giovanni Rotondo, Italy}

1) 14 Participants: 4 patients with cognitive impairment, 3 caregiver/relatives, 3 geriatrician, 1 psychologist, 1 nurse, 1 physicist and 1 engineer.

2) 10 Participants: 1 geriatrician, 1 psychologist, 1 physicist, 1 office worker, 3 computer scientists and 3 engineers. 


\section{MARIO Questionnaire 1/4}

\section{0 caregivers of patients with dementia}

consecutively recruited from May to November 2015 at:

$\square \mathbf{N}=\mathbf{7 0}$ - Geriatrics Unit, Casa Sollievo della Sofferenza, IRCCS, San Giovanni Rotondo, Italy (IRCCS)

$\square \mathbf{N}=39$ - National University of Ireland, Galway, Ireland (NUIG)

$\square \mathbf{N}=\mathbf{2 1}$ - Alzheimer Association Bari, Italy (AAB)

Inclusion criteria:

- Caregiver of patients with diagnosis of dementia according to the criteria of the National Institute on Aging-Alzheimer's Association (NIAAA)

- The ability to provide an informed consent or availability of a proxy for informed consent.

Exclusion criteria:

- Caregivers of patients with serious comorbidity, tumors and other diseases that could be causally related to cognitive impairment (ascertained blood infections, vitamin B12 deficiency, anaemia, disorders of the thyroid, kidneys or liver), history of alcohol or drug abuse, head trauma, psychoactive substance use and other causes of memory impairment. 


\section{MARIO Questionnaire 2/4}

The following parameters were collected by a systematic interview about the caregivers:

- Gender

- Age

- Educational level (in years)

- Caregiving type:

$\checkmark$ Informal caregiver (unpaid)

$\checkmark$ Informal caregiver (paid)

$\checkmark$ Formal caregiver (Geriatrician)

$\checkmark$ Formal caregiver (Psychologist)

$\checkmark$ Formal caregiver (Nurse) 


\section{MARIO Questionnaire 3/4}

1) A five-minute video on the first model of robot suggested at the begin of the MARIO project:

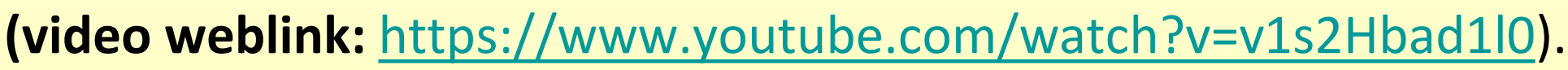

2) A 42-item questionnaire that evaluated the potential role of:

A) Acceptability

B) Functionality

C) Support devices

D) Impact

3) Responses were expressed as:

- "Extremely important/likely/useful" or "YES, very useful"

to

- "Not at all important/ likely/useful" or "Not useful at all". 


\section{MARIO Questionnaire 4/4}

\section{Items of the MARIO Questionnaire}

\begin{tabular}{|c|c|c|c|}
\hline Section A: Acceptability & Section B: Functionality & Section C: Support device & Section D: Impact \\
\hline How important is it that MARIO has: & How important is it that MARIO has: & $\begin{array}{l}\text { Do you think that the following } \\
\text { support devices in MARIO could be } \\
\text { useful for your patients? }\end{array}$ & $\begin{array}{l}\text { To what extent do you } \\
\text { think MARIO could be } \\
\text { useful in order to: }\end{array}$ \\
\hline 1 (Human like appearence) & 1 (Face recognition) & 1 (Bed rest) & 1 (Quality of life) \\
\hline 2 (Human sounding voice) & 2 (Voice recognition) & 2 (Medication use) & 2 (Quality of care) \\
\hline 3 (Familiar voice) & 3 (Distinguishing individuals) & 3 (Ambient environmental) & 3 (Safety) \\
\hline 4 (Covering like to touch) & 4 (Natural dialogue) & 4 (Lighting, TV channels) & $\begin{array}{l}4 \text { (Emergency } \\
\text { communication) }\end{array}$ \\
\hline 5 (Height adjustable) & 5 (Device for outside-home) & 5 (CGA) & $\begin{array}{l}5 \text { (Cognitive } \\
\text { rehabilitation) }\end{array}$ \\
\hline 6 (Not verbally comunication) & $\begin{array}{l}6 \text { (Prompts for } \\
\text { appointments) }\end{array}$ & 6 (Care planning) & $\begin{array}{l}6 \text { (Detecting } \\
\text { isolation) }\end{array}$ \\
\hline 7 (Displays emotional expression) & 7 (Person's life history) & 7 (Physiological deterioration) & $\begin{array}{l}7 \text { (Detecting health } \\
\text { status changes) }\end{array}$ \\
\hline 8 (Daily assistance reminder) & $\begin{array}{l}8 \text { (Communication by } \\
\text { multimedia) }\end{array}$ & 8 (Cognitive deterioration) & \\
\hline 9 (Monitor movement) & 9 (Voice activation) & & \\
\hline 10 (Entertainment) & 10 (Gesture recognition) & & \\
\hline 11 (Communication with caregivers) & 11 (Help for walking) & & \\
\hline 12 (Quiet robot) & 12 (Understanding dialects) & & \\
\hline 13 (Moving in home) & 13 (GPS function) & & \\
\hline
\end{tabular}




\section{Results 1/5}

Table 1. Characteristics of dementia caregivers.

\begin{tabular}{|c|c|c|c|c|c|}
\hline & ALL & NUIG & IRCCS & AAB & $P$ value \\
\hline & $N=130$ & $N=39$ & $\mathrm{~N}=70$ & $\mathrm{~N}=21$ & \\
\hline Gender (M/F) & $36 / 55$ & - & $28 / 42$ & $8 / 13$ & 0.876 \\
\hline $\begin{array}{l}\text { Age (years)* } \\
\text { range }\end{array}$ & $\begin{array}{c}48.12 \pm \\
15.81 \\
23-88\end{array}$ & - & $\begin{array}{c}48.74 \pm 14.90 \\
23-88\end{array}$ & $\begin{array}{c}45.72 \pm 19.25 \\
24-82\end{array}$ & 0.473 \\
\hline $\begin{array}{l}\text { Educational level (years)* } \\
\text { range }\end{array}$ & $\begin{array}{c}16.09 \pm 6.00 \\
0-24\end{array}$ & $\begin{array}{c}18.88 \pm 1.22 \\
18-23\end{array}$ & $\begin{array}{c}14.90 \pm 7.06 \\
0-23\end{array}$ & $\begin{array}{c}15.61 \pm 5.30 \\
5-24\end{array}$ & 0.006 \\
\hline \multicolumn{6}{|l|}{ Caregiving types } \\
\hline Informal caregiver (unpaid) $\mathbf{N}(\%)$ & $33(25.3)$ & $0(0)$ & $24(72.7)$ & $9(27.3)$ & \\
\hline Informal caregiver (paid) $\mathbf{N}(\%)$ & $7(5.4)$ & $0(0)$ & $6(85.7)$ & $1(14.3)$ & \\
\hline Formal caregiver (Geriatrician) $\mathbf{N}(\%)$ & $19(14.6)$ & $0(0)$ & $18(94.7)$ & $1(5.3)$ & $<0.0001$ \\
\hline Formal caregiver (Psychologist) N(\%) & $7(5.4)$ & $0(0)$ & $0(0)$ & $7(100.0)$ & \\
\hline Formal caregiver (Nurse) $\mathbf{N}(\%)$ & $57(43.9)$ & $32(56.1)$ & $22(38.6)$ & $3(5.3)$ & \\
\hline Not indicated (N\%) & $7(5.4)$ & $7(100.0)$ & $0(0)$ & $0(0)$ & \\
\hline
\end{tabular}

*Values are presented as mean \pm standard deviation. 


\section{Results 2/5}

Figure 1. Rate of "Extremely important/likely/useful" or "YES, very useful" answer by caregivers of dementia patients to the MARIO Questionnaire.

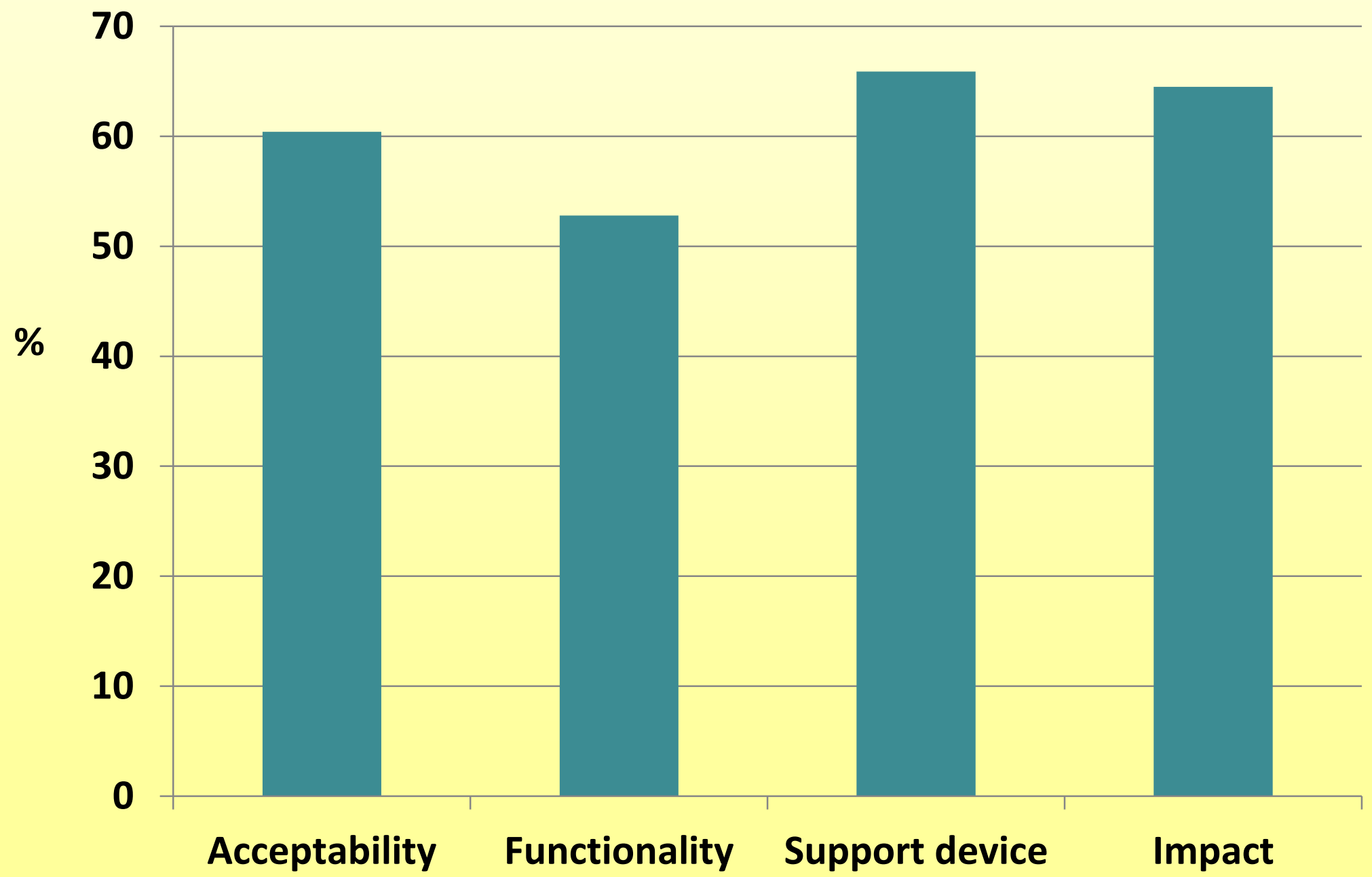




\section{Results 3/5}

Figure 2. "Extremely important/likely/useful" or "YES, very useful" answer by caregivers of dementia patients to the MARIO Questionnaire: effect of sex of caregivers

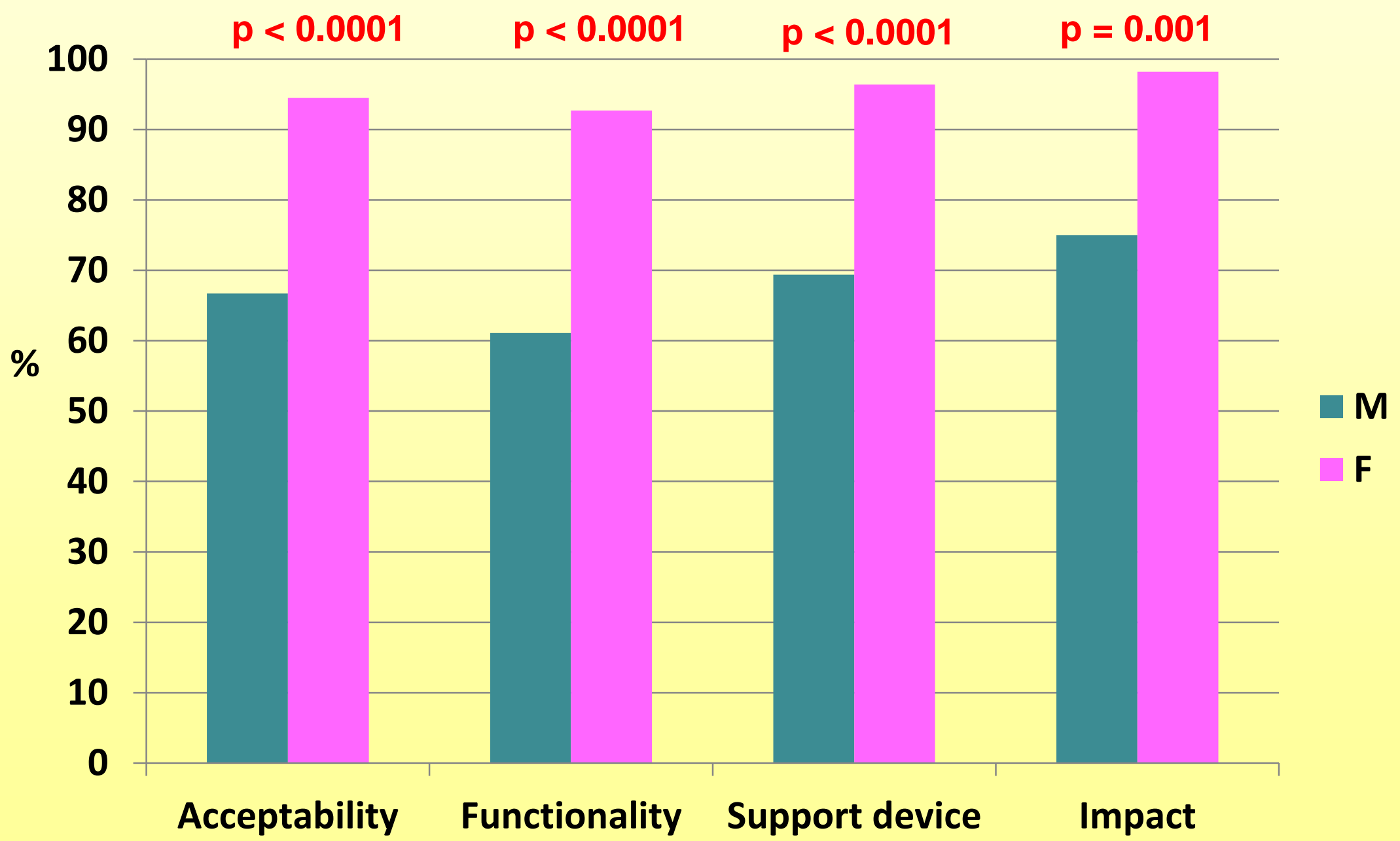




\section{Results 4/5}

Figure 3. "Extremely important/likely/useful" or "YES, very useful" answer by caregivers of dementia patients to the MARIO Questionnaire: effect of age of caregivers

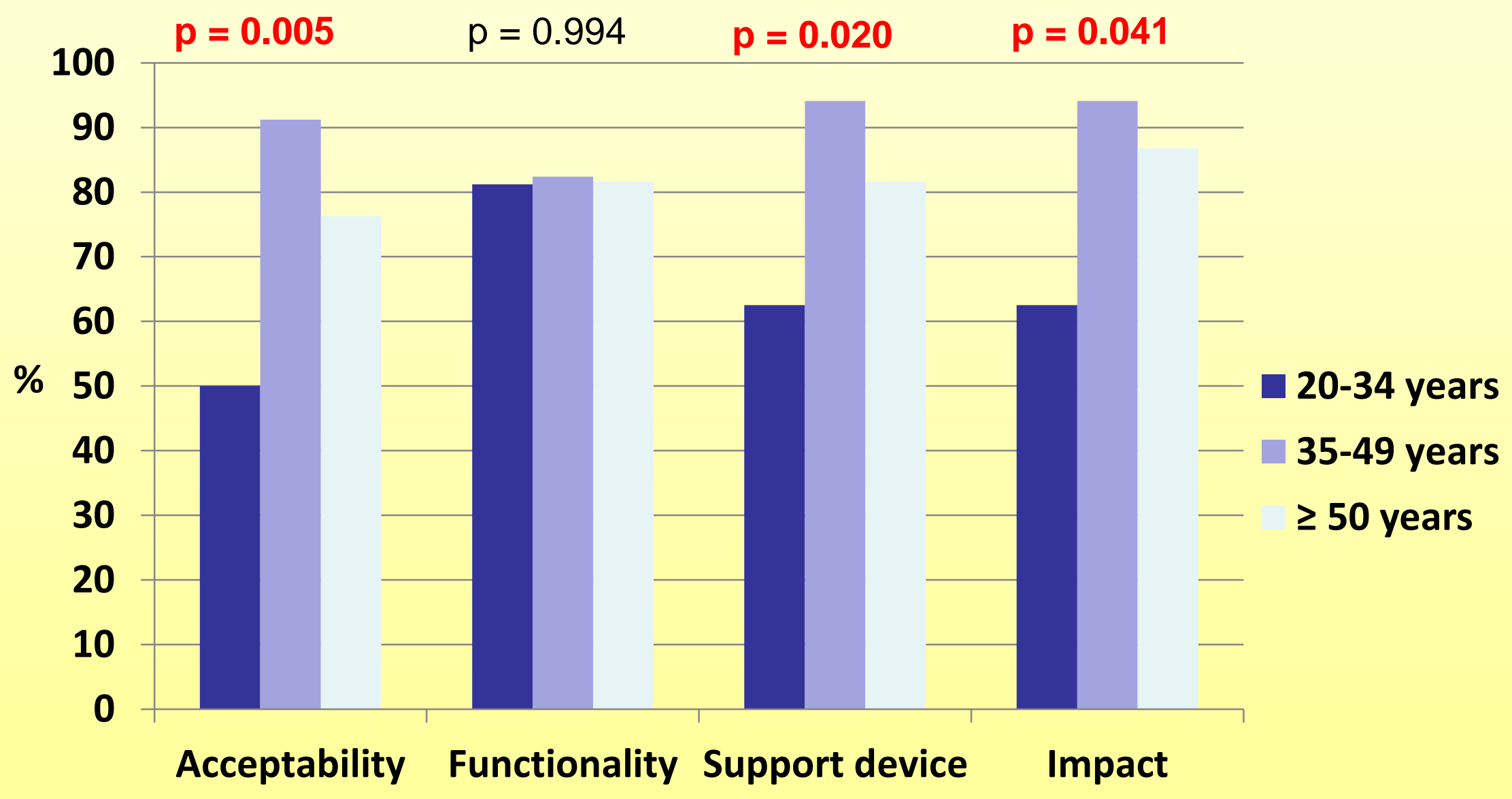




\section{Results 5/5}

Figure 4. "Extremely important/likely/useful" or "YES, very useful" answer by caregivers of dementia patients to the MARIO Questionnaire: effect of educational level of caregivers

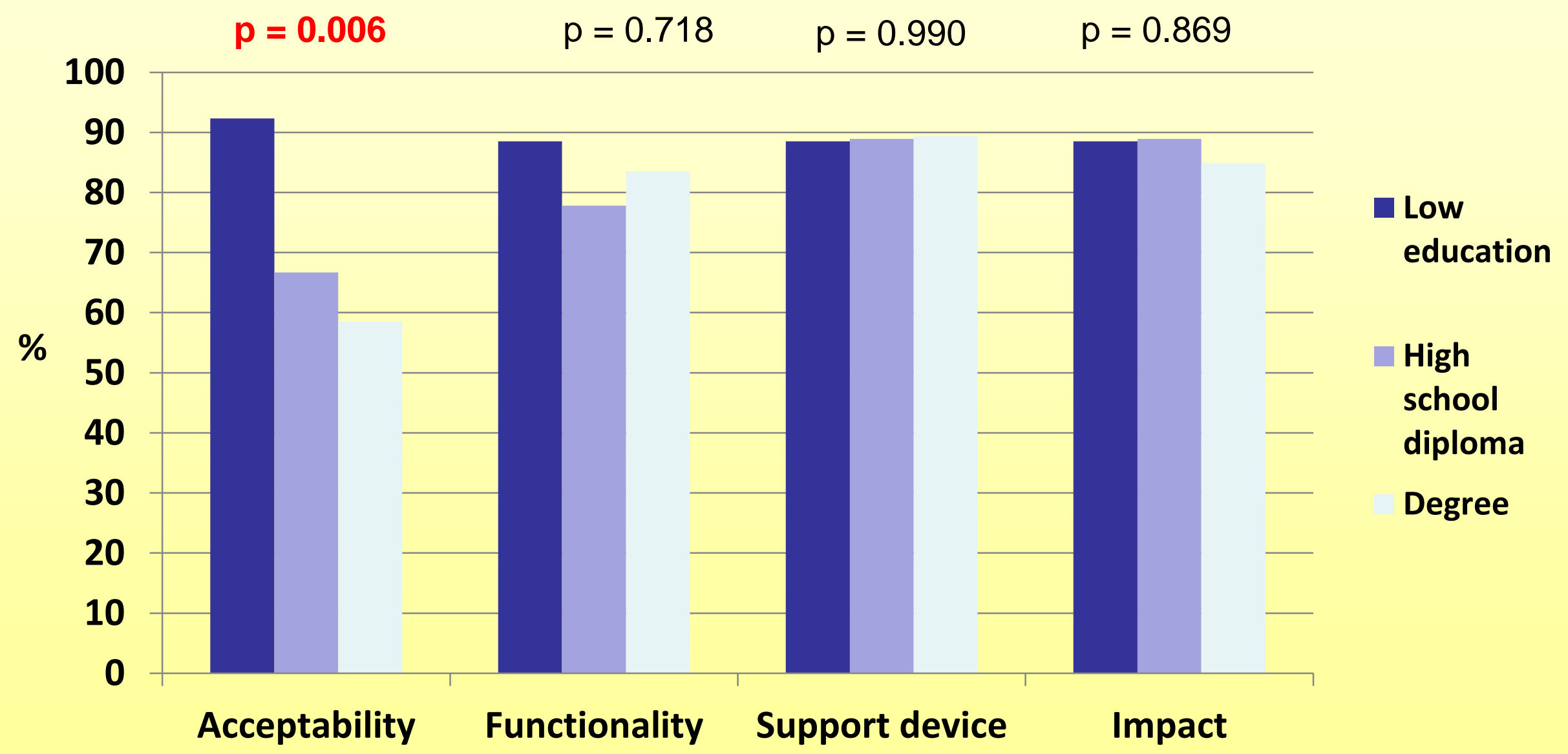




\section{Customization of the CGA}

The principal objective is to translate the CGA from a personal subjective based administration to a robotic objective system that can autonomously and continuously monitor a subject during an predefined time interval and can expand the possibility, accuracy and intervention efficacy

\section{Reviewing process about ICT used for CGA domains were performed:}

1. Cognitive stimulation and Information-Communication Technologies (ICT) in Alzheimer's disease: a systematic review

2. Insomnia and Assistive Technologies in elderly people: a systematic review

3. Intelligent Technologies (IT) for the Activities of Daily Living in elderly patients with dementia: a systematic review

4. Literature review on Technologies used to monitoring vital signs

5. Literature review on Assessment of Nutritional status

6. Literature review on Compliance to drug Treatment

7. State of the art in speech-based robot socialization

8. State of the art in robotic and sensor technologies for human mobility, and gait evaluation 


\section{Implementation stage}

For MARIO implementation the following sensors and apps are developping:

- Beddit Sleep Monitor

- FITBIT

- ZephyrLIFE ${ }^{\mathrm{TM}}$

- CGA app

- Music and Flash game apps

- News app

- Hobby app

- Dementia Friendly Communities (DFC) app 
MARIO arrived in Casa Sollievo della Sofferenza on August 24, 2016

The experimentation stage begins...

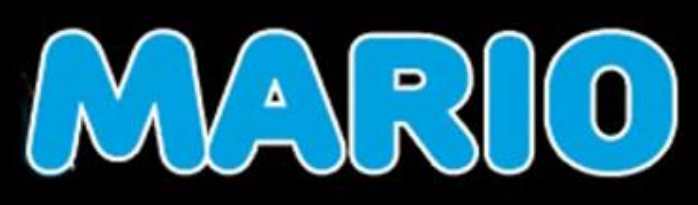




\section{Experimentation stage (September 2016): Preliminary results (1/3)}

We are administering a 13-item questionnaire that evaluates:

A) Acceptability

B) Functionality

19 patients with mild cognitive impairment ( $M=6, F=13)$ with a mean of educational level of $9.63 \pm 5.64$ 


\section{Experimentation stage: Preliminary results (2/3)}

Acceptability

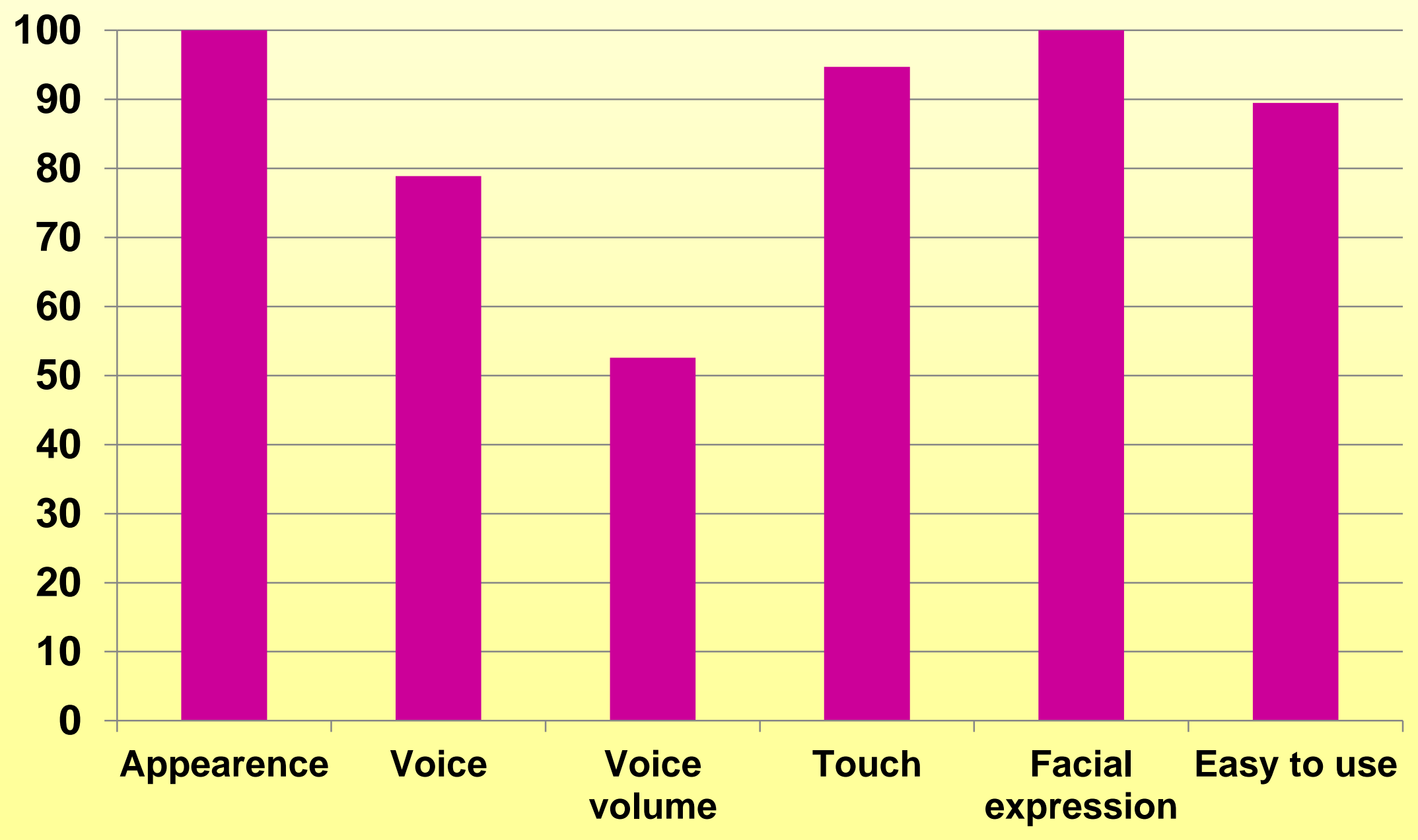




\section{Experimentation stage: Preliminary results (3/3)}

\section{Functionality}

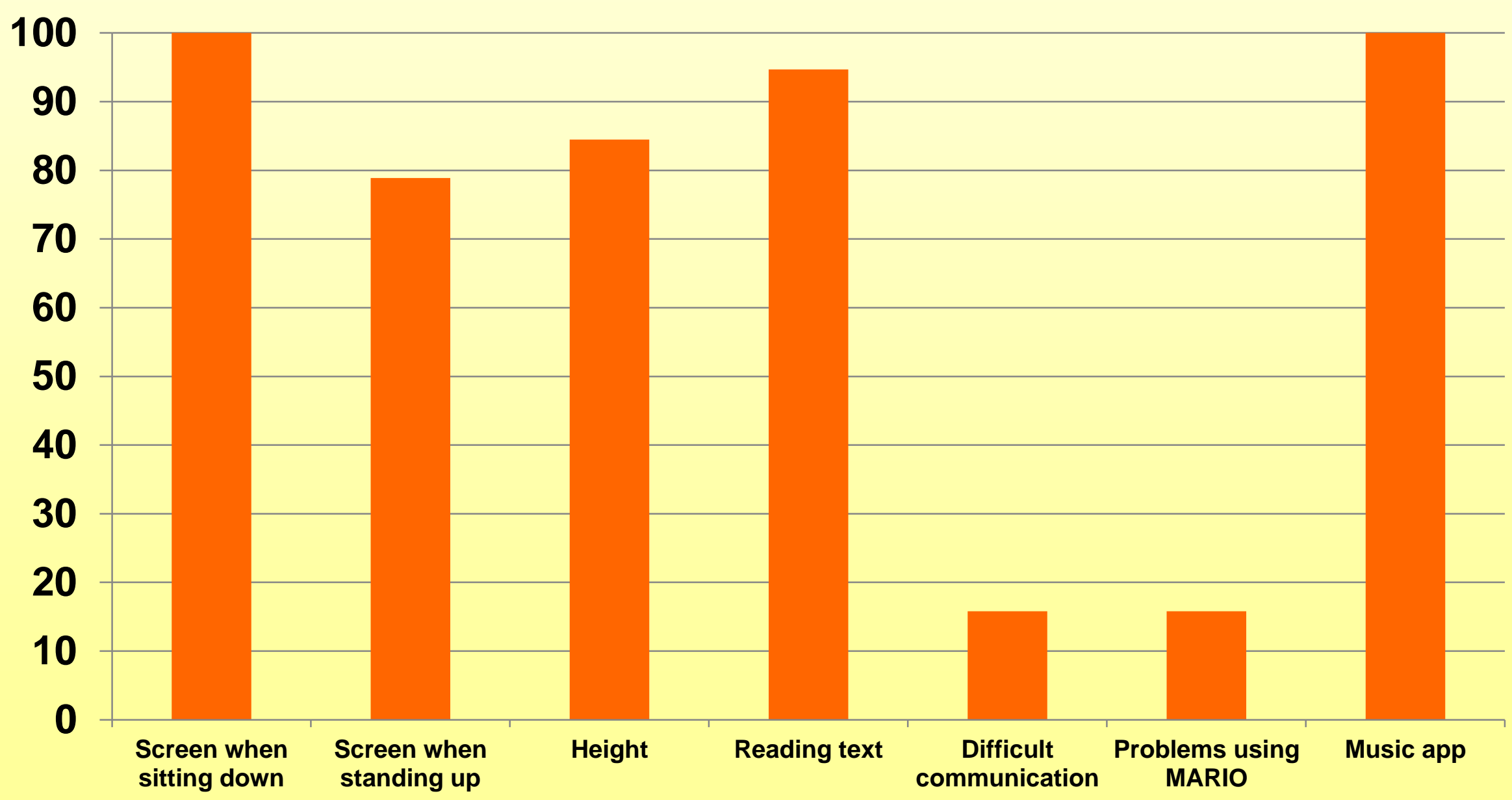




\section{First Trial \\ (November-December 2016): Material and Methods 1/2}

Inclusion criteria:

1) age $\geq 65$ years;

2) patients with diagnosis of mild dementia according to the criteria of the National Institute on Aging-Alzheimer's Association (NIAAA);

3) the ability to provide an informed consent or availability of a proxy for informed consent.

The patients were invited to use the following apps: My Music and My Games.

The patients interacted with MARIO $60 \mathrm{~min} /$ die in mean (respectively, a mean of $41 \mathrm{~min} /$ die for My Music app, and a mean of $19 \mathrm{~min} /$ die for My Games app) for a mean of 7.6 \pm 4.3 hospitalization days (range $=3-12$ days). 


\section{First Trial: \\ Material and Methods 2/2}

At admission and at discharge, the following parameters were collected:

- Demographic data

- Clinical and medication history

\section{Cognitive and affective assessment}

1. Mini Mental State Examination (MMSE)

2. Clinical Dementia Rating (CDR)

3. Clock Drawing Test (CDT)

4. Frontal Assessment Battery (FAB)

5. Hachinski Ischemic Scale (HIS)

6. Neuropsychiatric Inventory (NPI)

7. Geriatric Depression Scale (GDS-15)

8. Hamilton Rating Scale for Depression (HDRS-21)
Quality of life and

Caregiver burden level assessment

1. Quality of Life in Alzheimer's Disease (QOL-AD)

2. Caregiver Burden Inventory (CBI)

\section{Clinical Assessment}

1. Tinetti Balance Assessment (TBA)

2. Comprehensive Geriatric Assessment (CGA):

- Activities of Daily Living (ADL)

- Instrumental -ADL (IADL)

- Short Portable Mental Status Questionnaire (SPMSQ)

- Mini Nutritional Assessment (MNA)

- Scala di Exton-Smith (ESS)

- CIRS-comorbility (CIRS-Cl)

- Number of medications

- Co-habitational status

\section{Evaluation of social aspects and resilience}

1. Multidimensional Scale of Perceived Social Support (MSPSS)

2. Social Dysfunction Rating Scale (SDRS)

3. Brief Resilience Scale (BRS)

\section{Acceptability Assessment}

1. Almere Model Questionnaire (AMQ) 


\section{First Trial:}

\section{Results $1 / 2$}

5 patients $(M=3, F=2)$ with an average age of $74.20 \pm 10.0$ range $=66-86$ years

\begin{tabular}{|c|c|}
\hline - MMSE mean score $=19.66 \pm 1.67$ & $0 \pm 4.92$ \\
\hline - CDT mean score $=2.20 \pm 0.84$ & $=4.20 \pm 2.49$ \\
\hline - FAB mean sc & $v^{e}$ hean score $=4.80 \pm 3.56$ \\
\hline - NPI mean & SPMSQ mean score $=2.60 \pm 2.67$ \\
\hline - GDS-15 n & - CIRS mean score $=2.20 \pm 1.30$ \\
\hline - HRSD-2 & - MNA mean score $=23.00 \pm 6.04$ \\
\hline nitl $=14.96$ & - ESS mean score $=23.00 \pm 6.04$ \\
\hline $.20 \pm 4.60$ & - $\mathrm{N}$ of medications $($ mean $)=5.60 \pm 2.51$ \\
\hline $6.80 \pm 1.79$ & \\
\hline lean score $=32.80 \pm 5.72$ & \\
\hline - $C B I$ mean score $=18.00 \pm 6.93$ & \\
\hline
\end{tabular}


First Trial:

Results $2 / 2$

\begin{tabular}{|l|l|l|c|}
\hline \multicolumn{3}{|c|}{ Almere Model Questionnaire (1) } \\
\hline Code & Construct & Definition & $\%$ \\
\hline ANX & Anxiety & $\begin{array}{l}\text { Evoking anxious or emotional reactions when using } \\
\text { the system }\end{array}$ & $\mathbf{0}$ \\
\hline ATT & Attitude & $\begin{array}{l}\text { Positive or negative feelings about the appliance of } \\
\text { the technology }\end{array}$ & 100 \\
\hline FC & Facilitating condition & $\begin{array}{l}\text { Objective factors in the environment that facilitate } \\
\text { using the system }\end{array}$ & 60 \\
\hline ITU & Intention to use & $\begin{array}{l}\text { The outspoken Intention to Use the system over a } \\
\text { longer period in time }\end{array}$ & 60 \\
\hline PAD & Perceived adaptivity & $\begin{array}{l}\text { The perceived ability of the system to be adaptive to } \\
\text { the changing needs of the user }\end{array}$ & 100 \\
\hline PENJ & Perceived enjoiment & $\begin{array}{l}\text { Feelings of joy or pleasure associated by the user } \\
\text { with the use of the system }\end{array}$ & $\begin{array}{l}\text { The degree to which the user believes that using the } \\
\text { system would be free of effort }\end{array}$ \\
\hline PEOU & Perceived Ease of use & \begin{tabular}{l} 
The \\
\hline
\end{tabular}
\end{tabular}




\section{First Trial:}

\section{Results $2 / 2$}

\begin{tabular}{|l|l|l|c|}
\hline \multicolumn{3}{|c|}{ Almere Model Questionnaire (2) } \\
\hline Code & Construct & Definition & 80 \\
\hline PS & Perceived sociability & $\begin{array}{l}\text { The perceived ability of the system to perform } \\
\text { sociable behavior }\end{array}$ & 80 \\
\hline PU & Perceived usefulness & $\begin{array}{l}\text { The degree to which a person believes that using the } \\
\text { system would enhance his or her daily activities }\end{array}$ & 60 \\
\hline SI & Social influence & $\begin{array}{l}\text { The user's perception of how people who are } \\
\text { important to him think about him using the system }\end{array}$ & 40 \\
\hline SP & Social presence & $\begin{array}{l}\text { The experience of sensing a social entity when } \\
\text { interacting with the system }\end{array}$ & 60 \\
\hline TRUST & Trust & $\begin{array}{l}\text { The belief that the system performs with personal } \\
\text { integrity and reliability }\end{array}$ & 60 \\
\hline USE & Use/Usage & $\begin{array}{l}\text { The actual use of the system over a longer period in } \\
\text { time }\end{array}$ & \\
\hline
\end{tabular}


Conclusion 


\section{Thank you!}

- Aknowledgements

The research leading to these results has received funding from the European Union Horizons 2020 the Framework Programme for Research and Innovation (2014-2020) under grant agreement 643808 Project MARIO "Managing active and healthy aging with use of caring service robots"

- Contact

http://www.mario-project.eu/ 